\title{
What causes inefficient transmission of male-killing Wolbachia in Drosophila?
}

\author{
GREGORY D. D. HURST*†, FRANCIS M. JIGGINS $+\uparrow \&$ SARAH J. W. ROBINSON $\dagger$ \\ $\dagger$ Department of Biology, University College London, 4 Stephenson Way, London NW1 2HE, U.K. and $\ddagger$ Department \\ of Genetics, Downing Street, Cambridge, CB2 3EH, U.K.
}

\begin{abstract}
Selfish genetic elements that distort the sex ratio are common in arthropods. Theory predicts they will invade and spread to fixation if they are vertically transmitted with perfect fidelity, potentially leading to host extinction. For inherited microorganisms that distort the sex ratio, inefficient vertical transmission or incomplete sex ratio distorting ability is required for host persistence. However, the relative roles of genetic and environmental factors in permitting the survival of male hosts and preventing parasite transmission are poorly understood. We examined the causes of transmission infidelity and male survival for a male-killing Wolbachia strain in Drosophila bifasciata. Under standard laboratory conditions $\left(18^{\circ} \mathrm{C}\right)$, in its standard genetic background, males are produced very rarely, and no case of reversion has been observed in 20 generations of laboratory rearing. To investigate the role of host genetic factors, Wolbachia was crossed into 27 different inbred lines of D. bifasciata, but in no case was reversion observed at preferred environmental temperatures. The role of elevated temperature in inducing inefficient transmission was examined. Whilst vertical transmission was perfect over three generations of maintenance at $23.5^{\circ}$, transmission infidelity was observed at $25^{\circ}$. We conclude that there is no evidence for the presence of either fixed or polymorphic host genes that repress transmission at standard environmental temperatures. However, severe temperature treatment does make vertical transmission imperfect. We suggest that the case of Wolbachia in D. bifasciata is one that is naturally balanced, the population being maintained polymorphic without the evolution of host resistance genes.
\end{abstract}

Keywords: Drosophila, male killing, parasite resistance, selfish genetic elements, Wolbachia.

\section{Introduction}

It is now recognized that a large number of arthropods are host to selfish genetic elements that distort the sex ratio (Hurst et al., 1996). These are of two types. First, there are the cases of meiotic drive associated with sex chromosomes. Here, one of the sex chromosome gains a transmission advantage during male meiosis, such that it is inherited by more than half of the progeny of a male (Lyttle, 1991). Second, there are cases of maternally inherited agents that have evolved to distort the sex ratio of their host away from the production of male offspring (which cannot transmit them) towards the production of female offspring (Hurst et al., 1997). Three different types of cytoplasmic sex ratio distorters are known in arthropods. First, strains of Wolbachia are known which induce host parthenogenesis, through doubling the chromosome complement of haploid males in haplodiploid hosts (Stouthamer \& Kazmer, 1994; Stouthamer,

*Correspondence. E-mail: g.hurst@ucl.ac.uk
1997). Second, there are strains of both Wolbachia and members of the Microspora which alter the sex determination of their host, promoting female development of hosts that would otherwise be male (Rigaud, 1997). Lastly, there are a number of bacteria that kill male hosts during embryogenesis (Hurst \& Jiggins, 2000).

Hamilton (1967) recognized that selfish genetic elements that distort the sex ratio are in an interesting evolutionary position. If the ecological and biological circumstances permit, they may become fixed within the population and cause the extinction of both themselves and their host. Indeed, fixation of Wolbachia that induce host parthenogenesis is known, whole species being converted to asexuality (Zchori-Fein et al., 1992). For a microorganism that distorts host sex ratio rather than sexuality, this situation would correspond to host extinction.

Evolutionary biologists have therefore asked what factors prevent selfish genetic elements that distort the sex ratio from going to fixation, that is to say what factors maintain these elements balanced within the 
population (Carvalho \& Vaz, 1999). Two types of scenario are envisaged. First, there are cases in which the selfish genetic element is naturally balanced. That is to say, the element remains polymorphic in the population without host evolution. In the case of meiotic drive in Drosophila pseudoobscura, for instance, the effect of increased requirement for sperm that follows from female-biased population sex ratios is considered to impose selection on male virility and prevent the driving $\mathrm{X}$ chromosome (which reduces sperm production) becoming fixed in the population (Policansky, 1979). For inherited microorganisms that distort the sex ratio, natural balance may follow from inefficient transmission of the element due to environmental influences on microorganism survival. A variety of studies have demonstrated elevated environmental temperature reduce either the transmission efficiency of Wolbachia or the penetrance of its reproduction manipulation phenotypes (Hoffmann et al., 1986; Stevens, 1989; Rigaud et al., 1991; Pintureau et al., 1999; van Opijnen $\&$ Breeuwer, 1999). Other studies have suggested a role for naturally occurring antibiotics in reducing Wolbachia transmission rates (Stevens \& Wicklow, 1992). Second, there are cases where natural balance is lacking. Here, the element would become fixed were it not for host evolution. It is selection for host genes preventing the action or transmission of the element that maintains the element polymorphic in the host population. Genes that repress the distorting ability of driving $\mathrm{X}$ chromosomes are well known in a variety of systems, and resistance to driving genes is more common than 'natural balance' for genes inducing drive (Carvalho \& Vaz, 1999).

As yet there are insufficient case studies to assess the relative frequency with which inherited microorganisms that distort the sex ratio are balanced by environmental and host genetic factors. Whilst it is clear that genes preventing parasite transmission are important in certain cases (Cavalcanti et al., 1957; Rigaud \& Juchault, 1992), there is little data on the extent to which 'natural balance' exists. We therefore examined the causes of inefficient transmission of the male-killing Wolbachia in Drosophila bifasciata (Hurst et al., 2000). Drosophila bifasciata is a temperate zone fly that breeds predominantly in sap fluxes. The bacterium is present in between 0 and $7 \%$ of females from wild populations (Ikeda, 1970), suggesting that the factors inducing Wolbachia loss will be of detectable magnitude. Initially, we looked for evidence of polymorphic host factors preventing the transmission or action of this bacterium. Laboratory study of Wolbachia in D. bifasciata has shown it to be transmitted with perfect fidelity on the standard host genetic background (Ikeda, 1970). Ikeda (1970) further noted that the bacterium was faithfully transmitted in each of 10 inbred lines he maintained in the laboratory.

In this study we extended Ikeda's (1970) observation by testing a further 27 inbred lines. Following this, we looked for evidence of environmental effects on transmission fidelity. We show that exposure to elevated temperatures reduced transmission fidelity when temperature was maintained above $25^{\circ}$ over all life history stages. The lack of resistance genes, and the potential for elevated temperatures to induce transmission infidelity suggest that this system is balanced by environmental factors rather than by polymorphic host genes. These results are discussed in the context of other sex ratio distorting inherited microorganisms and selfish genetic elements in general.

\section{Methods}

\section{General methods}

Drosophila bifasciata were collected from Japan in 1998 as described in Hurst et al. (2000). Eighty isofemale lines were established, five of which were observed to bear male-killing Wolbachia. Members of the other 75 lines were pooled into a population and maintained at high population size ( $>1000$ flies) to prevent loss of genetic variation. These flies were bred on modified corn-meal agar, as in Hurst et al. (2000).

\section{Establishment of host environmental temperature}

The optimal conditions for fly development were reasoned to be those at which development was quick but mortality low. To ascertain the optimal temperature, outbred flies were allowed to oviposit at $21^{\circ} \mathrm{C}$, and replicates of 251 st instar larvae picked to vials maintained at $18^{\circ}, 21^{\circ}, 25^{\circ}$ and $27^{\circ}$, and at $70 \% \mathrm{RH}$. This was repeated for four different groups of ovipositing females. Time to emergence and survivorship to the adult stage were scored.

\section{Genetic variation for parasite transmission}

The genetic variation present in our outbred population of flies was converted into between-line variation through inbreeding. In brief, virgin females were taken from the outbred Japanese population, crossed to a single male and allowed to produce offspring. The new generation was then established from individual brother-sister crosses over a period of six generations, such that over $50 \%$ of heterozygous loci in the original pair of flies were converted to being homozygous. Overall, inbred lines from 25 founder pairs were constructed, and 
these were augmented by two inbred lines of European origin to give a total of 27 independent lines.

The response of the bacterium to the different genetic backgrounds was tested by introgressing the five different Wolbachia strains originally isolated from wild flies onto each of the different inbred backgrounds. For each inbred background, this was achieved by taking 5-10 virgin females from outbred Wolbachia-bearing matrilines, and mating to males from the inbred line over seven generations. After seven generations, each inbred line bearing Wolbachia was split into two parts, one half being maintained at $18^{\circ} \mathrm{C}$, the other half at $21^{\circ} \mathrm{C}$. The sex ratios produced by the lines were then monitored over three generations at each temperature.

\section{Effect of environmental temperature on the expression of male-killing and transmission of Wolbachia}

In order to investigate the effect of temperature on both the male-killing trait and the transmission of Wolbachia, replicate outbred populations of infected flies were subjected to a range of temperatures. To this end, eight populations of females bearing Wolbachia were outcrossed, and maintained at $18^{\circ} \mathrm{C}, 21^{\circ}, 23.5^{\circ}$ or $25^{\circ}$ over three generations, with males from the outbred population being introduced each generation (pilot experiments had established that inbred lines would not survive at elevated temperatures). The sex ratio was recorded on emergence of the new adult generation. If males were produced in any of the populations, we assayed for the presence of Wolbachia by removing 20-25 emerging female flies from across the eight populations to a low-temperature environment $\left(18^{\circ} \mathrm{C}\right)$, outcrossing them, and examining the sex ratio produced by individual females. Any of these flies producing more than $20 \%$ male offspring were considered candidates for having lost the bacterium, and their female progeny were subsequently crossed at $18^{\circ} \mathrm{C}$ and the sex ratio produced was scored. If this sex ratio was also $1: 1$, the originators were deemed uninfected.

Where loss of infection was detected in the above experiments, flies were kept at the end of the three generations of the experiment and tested for Wolbachia presence using a PCR assay. In brief, individual female flies were macerated and incubated at $56^{\circ} \mathrm{C}$ with $50 \mu \mathrm{L}$ of Chelex 100 ion exchange resin (Bio-Rad) in the presence of $200 \mu \mathrm{g} / \mathrm{mL}$ of proteinase-K. This was boiled, centrifuged and $1 \mu \mathrm{L}$ of the supernatant used directly for PCR. We tested for the presence of Wolbachia using the PCR primers $w s p 81 \mathrm{~F}$ and $w s p 691 \mathrm{R}$ that amplify the Wolbachia wsp gene (Zhou et al., 1998). The purity of templates that failed to amplify was tested by a PCR that amplifies the ITS-1 region from insect rDNA (Hillis \& Dixon, 1991). If this reaction was unsuccessful, the sample was removed from the analysis.

\section{Results}

\section{Establishment of preferred environmental temperature}

The stressful nature of elevated temperatures can be inferred from development speed and survivorship under different temperature conditions. In D. melanogaster, optimal development in terms of survival occurs at $25^{\circ} \mathrm{C}$, and development rate continues to accelerate beyond this point with increased mortality. In D. bifasciata, development is profoundly slower at $18^{\circ} \mathrm{C}$ than at $21^{\circ} \mathrm{C}$ (more than three days difference), but development rate was only marginally slower at $21^{\circ} \mathrm{C}$ than at $25^{\circ} \mathrm{C}(0.75$ days difference) (Table 1$)$. In contrast, mortality rapidly accelerated beyond $21^{\circ} \mathrm{C}$, with $21 \%$ egg to adult mortality at $18^{\circ} \mathrm{C}, 31 \%$ at $21^{\circ} \mathrm{C}$, $48 \%$ at $25^{\circ} \mathrm{C}$ and $100 \%$ at $27^{\circ} \mathrm{C}$ (Table 1). Excluding the data at $27^{\circ} \mathrm{C}$, there is still a significant interaction between temperature and mortality $(F=7.55,11,2$ d.f., $P=0.01)$. Summed together, this indicates that $21^{\circ} \mathrm{C}$ is a temperature at which development occurs at near maximum speed, but with lower mortality cost than at higher temperatures.

\section{Genetic variation for parasite transmission}

Wolbachia was successfully introgressed into the 25 inbred lines deriving from Japanese flies, and two inbred lines deriving from European flies. At $18^{\circ} \mathrm{C}, 23$ of 27 lines produced only females in the three generations of study. In the remaining four lines, just one male per line

\begin{tabular}{lccr}
\hline Temperature & $\begin{array}{c}\text { Mean female egg-adult } \\
\text { development time }\end{array}$ & $\begin{array}{c}\text { Mean male egg-adult } \\
\text { development time }\end{array}$ & $\begin{array}{c}\text { Mean no. } \\
\text { of deaths }\end{array}$ \\
\hline $18^{\circ} \mathrm{C}$ & $18.98(0.023)$ & $18.88(0.056)$ & $5.25(0.63)$ \\
$21^{\circ} \mathrm{C}$ & $15.35(0.012)$ & $15.68(0.069)$ & $7.75(1.89)$ \\
$25^{\circ} \mathrm{C}$ & $14.59(0.11)$ & $14.53(0.207)$ & $12.00(0.82)$ \\
$27^{\circ} \mathrm{C}$ & - & - & $25.00(0.00)$ \\
\hline
\end{tabular}

Table 1 The development time (in days) and mortality of Drosophila bifasciata maintained at different temperatures. Values are means of four replicates per treatment, and deaths are scored out of a total of 25 individuals. Between-replicate standard errors are given in parentheses 
was produced in families of over 150 flies. At $21^{\circ} \mathrm{C}, 25$ of the 27 lines gave rise to perfect all-female broods. The two remaining lines produced one son in 190 progeny, and two in 410 .

We found no evidence of any polymorphic or fixed host genes affecting parasite transmission or action under a 'standard' environmental regime. Any genes reducing Wolbachia transmission efficiency or preventing Wolbachia male-killer action are at very low frequency.

\section{Effect of environmental temperature on the expression of male-killing and transmission of Wolbachia}

Exposure of replicate fly populations to elevated temperatures over three generations was observed to induce male production only at $25^{\circ} \mathrm{C}$. Males were never observed at $18^{\circ} \mathrm{C}, 21^{\circ} \mathrm{C}$ or $23.5^{\circ} \mathrm{C}$. In contrast, males were produced at $25^{\circ} \mathrm{C}$ in all three generations $(17 \%$ males in the parental generation with $30-40 \%$ males in subsequent generations) (Fig. 1). We conclude that there is a sharp threshold for the production of males between $23.5^{\circ} \mathrm{C}$ and $25^{\circ} \mathrm{C}$. Further, absence of males at $23.5^{\circ} \mathrm{C}$ and below indicate transmission efficiency is near $100 \%$ at these temperatures, reinforcing the conclusion that no resistance genes act at these temperatures.

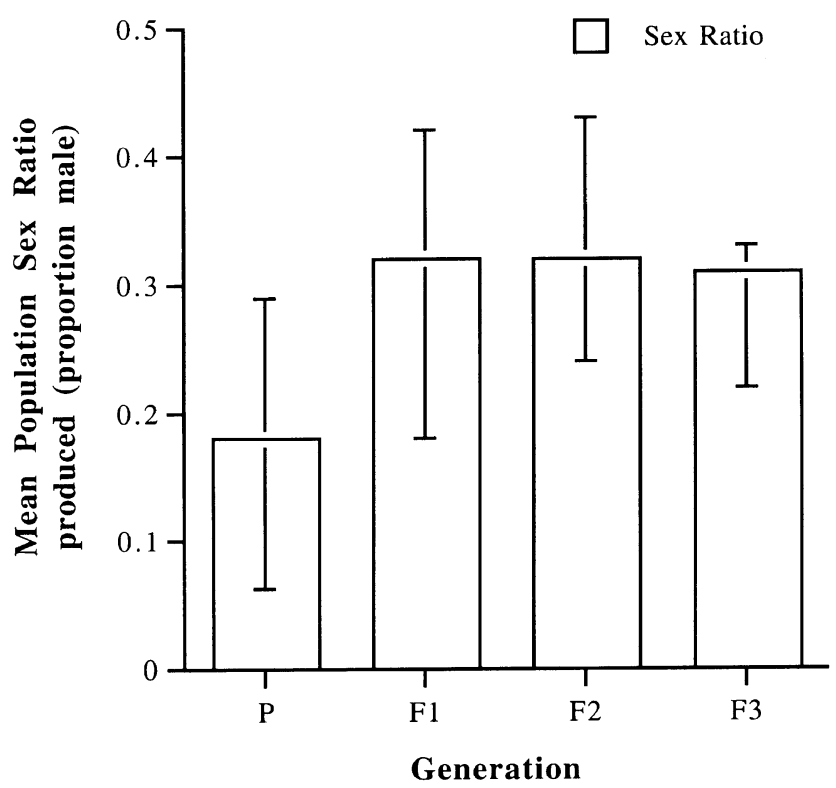

Fig. 1 The median sex ratio (proportion male) arising from eight populations of Drosophila bifasciata infected with a malekilling Wolbachia over a series of generations of exposure to $25^{\circ} \mathrm{C}$. Error bars indicate inter-quartile range.
The proportion of female flies infected in each generation of exposure was deduced from females removed from elevated-temperature populations, infection status being assayed through sex ratio produced at $18^{\circ} \mathrm{C}$. None of 17 females tested after one generation at $25^{\circ} \mathrm{C}$ produced a $1: 1$ sex ratio, and we can conclude that all females tested were still infected at this stage (Fig. 2). After two generations of exposure to elevated temperature, two of 22 females produced a normal sex ratio at $18^{\circ} \mathrm{C}$, a reversion that was permanent and heritable. After three generations, three of 19 females had lost the infection, and after four generations, seven of 25 females tested were uninfected. In addition to these females, tests of the populations at the end of the experiment by PCR assay indicated 20 of 81 females tested had lost the infection.

We conclude from these experiments that there is a threshold between $23.5^{\circ} \mathrm{C}$ and $25^{\circ} \mathrm{C}$ for the production of males by infected females. Protracted exposure to elevated temperatures can also induce inefficiencies in vertical transmission. After four generations of exposure to $25^{\circ} \mathrm{C}, 27$ of 106 females were uninfected $(25.5 \%)$. This represents a mean per generation transmission efficiency of $92.9 \%$ at elevated temperature.

\section{Discussion}

Studies of sex chromosomes that exhibit meiotic drive have suggested interactions between host and selfish genetic elements are of two kinds (Carvalho \& Vaz, 1999). First, there are cases where the interaction is naturally balanced, with the interaction remaining stable following drive invasion without evolution on either side. This is thought to be the case in the interaction between driving $\mathrm{X}$ chromosomes and their host in Drosophila pseudoobscura and Drosophila neotestacea, where strenuous efforts have failed to reveal the presence of any autosomal genes that prevent the action of meiotic drive (Policansky \& Dempsey, 1978; James \& Jaenike, 1990). Second, there are interactions where the driving gene would go to fixation and cause population extinction were it not for the invasion of resistance genes in the host population. Genes preventing the action of meiotic drive genes are well known (Carvalho \& Klaczko, 1993; Stalker, 1961; Voelker, 1972; Merçot et al., 1995; Jaenike, 1999). The evidence gathered to date suggest that the majority of cases of sex chromosome drive have host resistance genes as a force balancing these interactions (Carvalho \& Vaz, 1999; Jaenike, 1999). The same appears to be true for cases of cytoplasmic male sterility in plants.

The role of genes in preventing the action and transmission of inherited microorganisms that distort the sex ratio is less well characterized. Previous studies of 
F1

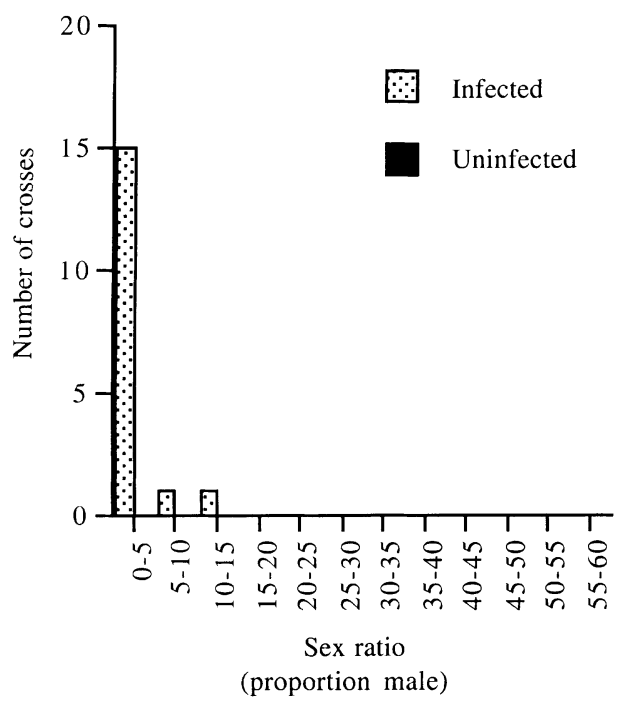

F3

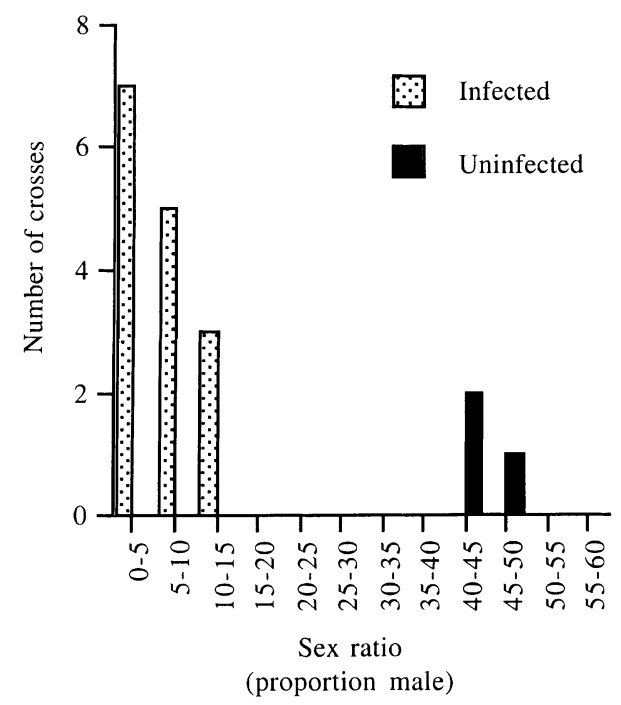

F2

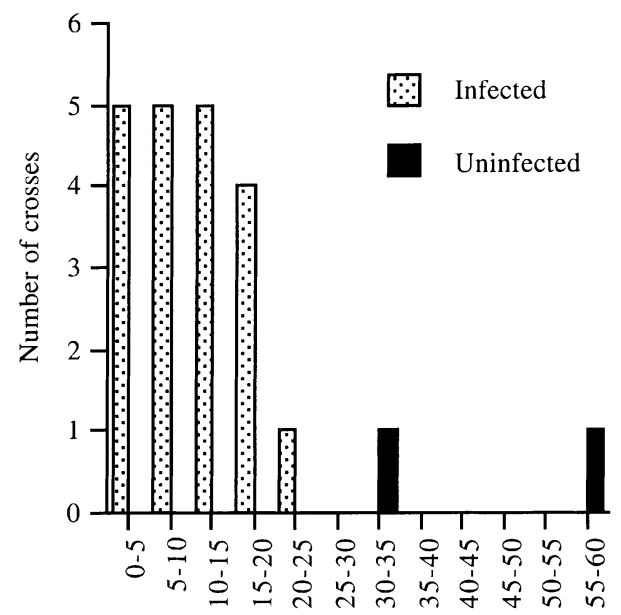

Sex ratio

(proportion male)

F4

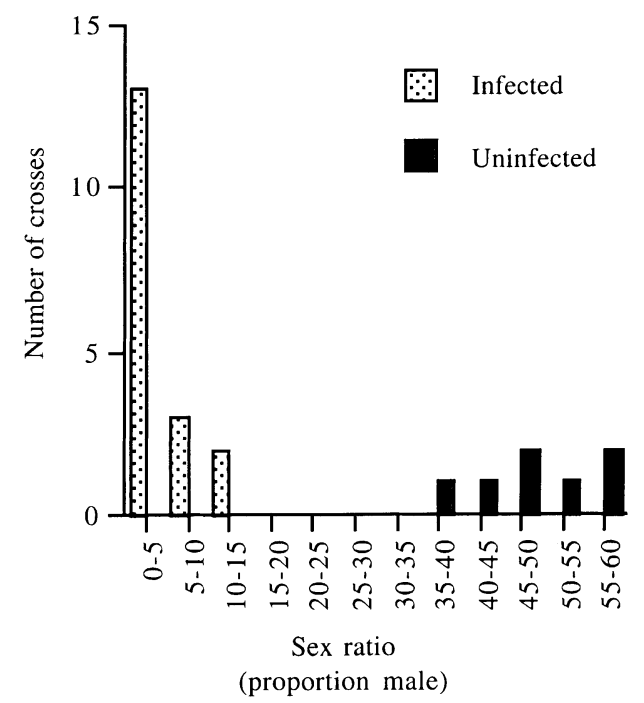

Fig. 2 The sex ratio produced (proportion male) by individual females removed from populations of Drosophila bifasciata infected with Wolbachia maintained at $25^{\circ} \mathrm{C}$ over a series of generations, and bred at $18^{\circ} \mathrm{C}$. Top left, $\mathrm{F} 1$ : flies removed after parental and larval exposure only. Top right, F2: flies removed after two generations of exposure to $25^{\circ} \mathrm{C}$. Bottom left, F3: flies removed after three generations of exposure to $25^{\circ} \mathrm{C}$. Bottom right, F4: flies removed after four generations of exposure to $25^{\circ} \mathrm{C}$. Black bars indicate females demonstrated to have lost infection.

male-killing in Drosophila have implicated genetic factors where sought (Cavalcanti et al., 1957; Malogolowkin, 1958), and these are echoed by evidence of host genetic factors resisting the transmission of the feminizing Wolbachia in Armadillidium vulgare (Rigaud \& Juchault, 1992). Our study, in contrast, found no evidence for genetic variation in host genes affecting bacterial transmission or male-killing action. The Wolbachia was perfectly transmitted in all the inbred genetic backgrounds tested in this study and killed males with near perfect efficiency. This echoes Ikeda's (1970) more limited study, and brings the total of inbred lines tested to 37. In addition, the absence of host factors influencing parasite transmission is indicated by the perfect transmission of the trait in outbred populations maintained at $18^{\circ} \mathrm{C}, 21^{\circ} \mathrm{C}$ and $23.5^{\circ} \mathrm{C}$. 
We conclude that any host genetic effects in D. bifasciata involve interaction with the environment, and none operate at the preferred environmental temperature for this species. The study therefore suggests that 'natural balance' can also exist for inherited microorganisms that distort the sex ratio. How common will natural balance be? At the moment there are two cases where host resistance genes are considered likely, and this one where they are considered unlikely. Beyond its limited sample size, it should be noted that even this 2:1 ratio should be treated with caution. Resistance genes for sex ratio distorting microorganisms are found and reported most commonly as the fortuitous (but interesting) result of loss of expression of these elements in the routine maintenance of sex ratio distorting lines within laboratory culture. Failure to find such genes is not reported as they do not attract scientific curiosity and are unpublishable without focused initial study. This has almost certainly led to an under-representation of these cases in the literature. Rigorous study designed to examine presence or absence of resistance genes in a variety of systems is clearly required.

Beyond insight into the evolutionary genetics of sex ratio distorting inherited microorganisms, the data also support the findings of Hurst et al. (2000) that the malekilling action of Wolbachia is more easily suppressed by exposure to elevated temperature than its transmission. In the study of Hurst et al. (2000), short exposure to elevated temperatures $\left(26^{\circ} \mathrm{C}\right)$ did not induce transmission loss but did reduce both bacterial density and malekilling efficiency. The more prolonged exposure in this study (albeit at the reduced temperature of $25^{\circ} \mathrm{C}$ ) reduced male-killing efficiency still further $(\approx 15 \%$ male production from parents exposed to high temperatures, increasing to $30-40 \%$ in subsequent generations), and also began to produce stochastic transmission infidelity. This is consistent with a progressive effect of elevated temperature on bacterial density, eroding first malekilling ability and then producing inefficient transmission as bacterial numbers decline still further. It is notable that the temperature stress required to reduce Wolbachia male-killing expression and induce inefficient transmission in this system is lower than that found in previous studies. Temperatures of $37^{\circ} \mathrm{C}$ and $32^{\circ} \mathrm{C}$ are sufficient to cure Wolbachia infection in Tribolium confusum and the two-spotted spider mite, respectively (Stevens, 1989; van Opijnen \& Breeuwer, 1999). Repression of the reproductive manipulation phenotypes of Wolbachia are seen at $30^{\circ} \mathrm{C}$ in Armadillidium vulgare and Trichogramma cordubensis, and at $28^{\circ} \mathrm{C}$ in D. simulans (Hoffmann et al., 1986; Rigaud et al., 1991; Pintureau et al., 1999). The susceptibility of the Wolbachia in D. bifasciata to temperatures below this level may reflect a reduced risk of exposure of
D. bifasciata to elevated temperature in the field. Although it inhabits the same temperate regions as some of these other species, it tends to migrate to mountain forests during the hot summer, potentially limiting exposure to high $\left(30^{\circ} \mathrm{C}\right)$ temperatures.

Finally, we can examine the degree to which the temperature effect demonstrated in this study explains loss of infection. It is important to note that our study does not exclude the possibility of other factors stabilizing the infection within D. bifasciata. Three main possibilities have been described. First, if the host has a metapopulation structure, and populations with high prevalence of sex ratio distorters have higher extinction risk, the population may remain polymorphic due to group selection effects. There is evidence for this in the case of cytoplasmic male sterility of Thymus vulgaris (Mannicacci et al., 1996). Second, if there is a costly mating preference exhibited by males for uninfected females, infected females are more likely to go unmated and this may produce a stable equilibrium (Randerson et al., 2000). This later explanation is more speculative, though the association between infection status and virginity in Acraea encedon is suggestive (Jiggins et al., 2000). Third, there is the possibility of natural cure of the trait associated with the presence of antibiotics within the environment (Stevens \& Wicklow, 1992) or following overwintering (Perrot-Minnot et al., 1996).

The first two explanations are unlikely in the case of the Wolbachia-D. bifasciata interaction. If selection at the level of the deme were important, we would expect to find demes with very female-biased sex ratios in the wild. However, populations surveyed never exceed $10 \%$ prevalence of the bacterium (Ikeda, 1970). In terms of mate choice, low parasite prevalence and concomitant low population sex ratio bias make it very unlikely that female flies within this system suffer from lack of mate availability.

Inefficient transmission remains the best hypothesis for the stability of this system. Elevated environmental temperature steadily erodes bacterial density and increases the probability of stochastic loss at the same time as lowering the probability with which males are killed. Additional study of the potential role of environmental antibiotics and overwintering on Wolbachia survival in wild females would be timely.

\section{Acknowledgements}

We wish to thank the BBSRC (D. Phillips Fellowship to GH) and Emmanuel College (Fellowship to FJ) for financial support, Dr A. Pomiankowski, Joanna Bentley and Emily Dyson for reading the manuscript, and anonymous reviewers for comments. 


\section{References}

CARVAlHo, A. B. AND KLACZKo, L. B. 1993. Autosomal suppressors of sex ratio in Drosophila mediopunctata. Heredity, 71, $546-551$.

CARvalho, A. B. AND vaz, s. C. 1999. Are Drosophila SR drive chromosomes always balanced? Heredity, 83, 221-228.

CAVAlCANTI, A. G. L., FAlCAO, D. N. AND CASTRO, L. E. 1957. 'Sex-ratio' in Drosophila prosaltans - a character due to interaction between nuclear genes and cytoplasmic factors. Am. Nat., 91, 327-329.

HAMilton, w. D. 1967. Extraordinary sex ratios. Science, 156, 477-488.

HILlis, D. M. AND DIXON, M. T. 1991. Ribosomal DNA: molecular evolution and phylogenetic inference. $Q$. Rev. Biol., 66, 411-453.

HOFFMANN, A. A., TURELli, M. AND Simmons, G. M. 1986. Unidirectional incompatibility between populations of Drosophila simulans. Evolution, 40, 692-701.

HURST, G. D. D. AND JIGGINS, F. M. 2000. Male-killing bacteria in insects: mechanisms, incidence and implications. Emerging Infectious Diseases, 6, 329-336.

Hurst, L. D., ATlan, A. AND Bengtsson, B. 1996. Genetic conflicts. Quart. Rev. Biol., 71, 317-364.

HURST, G. D. D., HURST, L. D. AND MAJERUS, M. E. N. 1997. Cytoplasmic sex ratio distorters. In: O'Neill, S. L., Hoffmann A. A. and Werren, J. H. (eds) Influential Passengers: Microbes and Invertebrate Reproduction, pp. 125-154. Oxford University Press, Oxford.

HURST, G. D. D., JOHNSON, A. P., SCHULENBURG, J. H. G. V. d. AND FUYAMA, Y. 2000. Male-killing Wolbachia in Drosophila: a temperature sensitive trait with a threshold bacterial density. Genetics, 156, 699-709.

IKEDA, H. 1970. The cytoplasmically-inherited 'sex-ratio' condition in natural and experimental populations of Drosophila bifasciata. Genetics, 65, 311-333.

JAENIKE, J. 1999. Suppression of sex-ratio meiotic drive and the maintenance of Y-chromosome polymorphism in Drosophila. Evolution, 53, 164-174.

JAMES, A. C. AND JAENIKE, J. 1990. 'Sex ratio' meiotic drive in Drosophila testacea. Genetics, 126, 651-656.

JigGins, F. M., HURST, G. D. D. AND MAJERUS, M. E. N. 2000. Sex ratio distorting Wolbachia causes sex role reversal in its butterfly host. Proc. R. Soc. B, 267, 69-73.

LytTLE, T. W. 1991. Segregation distorters. Ann. Rev. Genet., 25, 511-557.

MALOGOLOWKIN, C. 1958. Maternally inherited 'sex-ratio' condition in Drosophila willistoni and Drosophila paulistorum. Genetics, 43, 274-286.

MANNICACCI, D., COUVET, D., BELHASSEN, E., GOUYON, P.-H. ET AL. 1996. Founder effects and sex-ratio in the gynodioecious Thymus vulgaris L. Mol. Ecol., 5, 63-72.

MERÇOT, H., ATLAN, A., JACQUES, M. AND MONTCHAMP-MOREAU, C. 1995. Sex-ratio distortion in Drosophila simulans: co-occurrence of a meiotic driver and a suppresser of drive. J. Evol. Biol., 8, 283-300.

VAN OPIJNEN, T. AND BREEUWER, J. A. J. 1999. High temperatures eliminate Wolbachia, a cytoplasmic incompatibility inducing endosymbiont, from the two-spotted spider mite. Exp. Appl. Acarol., 23, 871-881.

PERROT-MINNOT, M.-J., GUO, L. R. AND WERREN, J. H. 1996. Single and double infections with Wolbachia in the parasitic wasp Nasonia vitripennis: effects on compatibility. Genetics, 143, 961-972.

Pintureau, B., CHAPElle, L. AND DELOBEl, B. 1999. Effects of repeated thermic and antibiotic treatments on a Trichogramma (Hym., Trichogrammatidae) symbiont. J. Appl. Ent., 123, 473-483.

POLICANSKY, D. 1979. Fertility differences as a factor in the maintenance of the 'sex-ratio' polymorphism in Drosophila pseudoobscura. Am. Nat., 114, 672-680.

POLICANSKY, D. AND DEMPSEY, B. 1978. Modifiers and 'sex ratio' in Drosophila pseudoobscura. Evolution, 32, 922-924.

RANDERSON, J. P., JigGins, F. M. AND HURST, L. D. 2000. Male killing can select for male mate choice: a novel solution to the paradox of the lek. Proc. R. Soc. B, 267, 867-874.

RIGAUD, T. 1997. Inherited microorganisms and sex determination of arthropod hosts. In: O'Neill, S. L., Hoffmann A. A. and Werren, J. H. (eds) Influential Passengers: Inherited Microorganisms and Arthropod Reproduction, pp. 81-102. Oxford University Press, Oxford, U.K.

RIGAUD, T. AND JUCHAUlT, P. 1992. Genetic control of the vertical transmission of a cytoplasmic sex factor in Armadillidium vulgare. Heredity, 68, 47-52.

RigAud, T., JUCHAUlt, P. AND MOCQUARD, J. P. 1991. Experimental study of temperature effects on the sex ratio of broods in the terrestrial Crustacean Armadillidium vulgare Latr. Possible implications in natural populations. J. Evol. Biol., 4, 603-617.

STALKER, H. D. 1961. The genetic systems modifying meiotic drive in Drosophila paramelanica. Genetics, 46, 177-202.

STEVENS, L. 1989. Environmental factors affecting reproductive incompatibility in flour beetles. J. Invert. Path., 53, 73-84.

STEVENS, L. AND WICKLOW, D. T. 1992. Multispecies interactions affect cytoplasmic incompatibility in Tribolium flour beetles. Am. Nat., 140, 642-653.

STOUTHAMER, R. 1997. Wolbachia-induced parthenogenesis. In: O’Neill, S. L., Hoffmann A. A. and Werren, J. H. (eds) Influential Passengers: Inherited Microorganisms and Invertebrate Reproduction, pp. 102-124. Oxford University Press, Oxford, U.K.

STOUTHAMER, R. AND KAZMER, D. 1994. Cytogenetics of microbe-associated parthenogenesis and its consequence for gene flow in Trichogramma wasps. Heredity, 73, $317-327$.

VOELKer, R. A. 1972. Preliminary characterization of 'sex ratio' and rediscovery and reinterpretation of 'male sex ratio' in Drosophila affinis. Genetics, 71, 597-606.

ZCHORI-FEIN, E., ROUSH, R. T. AND HUNTER, M. S. 1992. Male production influenced by antibiotic treatment in Encarsia formosa (Hymenoptera: Aphelinidae), an asexual species. Experientia, 48, 102-105.

ZHOE, W. F., ROUSSET, F. AND O'NEILL, S. L. 1998. Phylogeny and PCR based classification of Wolbachia strains using wsp gene sequences. Proc. R. Soc. Land. B, 265, 509-515. 